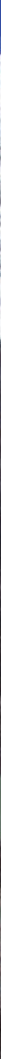

\title{
When the ice melts
}

\section{Deep in the Himalayas, the disappearance of glaciers is threatening the kingdom of Bhutan. Anjali Nayar trekked through the mountains to see how the country is adapting to a warming world.}

K

aka Tshering loops a piece of frayed jute rope around a 150-kilogram boulder. A handful of his fellow workers line up on either end and pull the rope taught. "Shochi, Shoni," the workers call in unison, as they heave. Their voices are raspy from the 4,400-metre altitude and moist, cold air. "Put your strength together."

After rocking a couple of times, the boulder rolls over and the labourers tumble backwards. Their cries are drowned out by the furious work around them as more than 300 men and women scrape away rocks with spades and shovels to reach their daily quota.

The work force is a cross-section of life in Bhutan. There are a number of young dropouts from the capital Thimphu, with greasy, shoulder-length hair and tattoos running up their forearms. Retired soldiers from the Royal Bhutan Army labour alongside former students of Buddhism. There are a handful of women in their traditional tartan-style robes, beaded necklaces and antique silver and turquoise brooches.

Together in matching hard hats and leaky rubber boots, they make up Bhutan's army against the effects of climate change. Their task is to deepen and widen the outlet channel from lakes formed by the rapidly melting Thorthormi glacier (pictured above, to the right of the lake). By helping the water to drain faster, Bhutanese officials hope to prevent a catastrophic flood.

Glaciers in the Himalayas are retreating faster than in any other part of the world and they could disappear completely by 2035 (ref. 1). This puts the mountainous nation of Bhutan at a special risk. In an area smaller than Switzerland, it has 983 glaciers and 2,794 glacial lakes, some of which have burst to produce deadly glacial lake floods.

As a poor nation without even its own helicopter, Bhutan lacks the resources to combat global warming. It is carrying out the work at Thorthormi glacier with the help of money from various international donors, including US $\$ 3.5$ million from the Least Developed Countries Fund, created under the United Nations Framework Convention on Climate Change. The global cost of adaptation could total hundreds of billions of dollars a year - orders of magnitude more than what is available to poor countries at the moment. During December's UN talks in Copenhagen, developing countries will be pushing for more generous - and reliable - funding to help them mitigate the impacts of climate change. As the first nation to get adaptation money from the Least Developed Countries Fund (see 'The long wait for adaptation money', page 1045), Bhutan is something of a pioneer among developing nations in their quest to adapt to a warmer future. And the struggles at Thorthormi glacier illustrate the enormous obstacles that adaptation efforts still face.

\section{Dangerous dam}

The sounds of global warming are deafening at Thorthormi glacier. Every few minutes, a block of ice rips off the glacier and crashes into the lake in a trail of dust and ice. These are some of the tallest mountains in the world and form Bhutan's northern boundary with Tibet.

To get a look at the hazard posed by the melting glacier, Karma Toeb, the project's glaciologist and team leader, scrambles to the top of a moraine - a steep ridge of loose, angular boulders built up by the glacier as it pushes debris along its edges. This moraine is a dam between two bodies of water (see map, overleaf). To the east, Toeb points out how several slushy grey-brown ponds have formed 


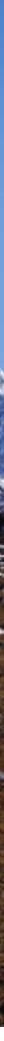

on top of the Thorthormi glacier. To the west lies a much larger lake (pictured above) called Rapstreng - vast and milky green - about 80 metres lower in elevation. Toeb first came to this site in 1997, during a project to shrink Rapstreng lake. Over three years, a thousand labourers widened and deepened Rapstreng's natural outlet to lower the lake by 4 metres.

At the time, nobody was worried about the Thorthormi glacier next door. "Thorthormi was almost pure ice," says Toeb. "We could cross over and walk on the glacier to do our research." The glacial lake didn't even appear in an exhaustive study of the region's dangerous lakes in 2001 by the International Center for Integrated Mountain Development (ICIMOD), based in Kathmandu, Nepal ${ }^{2,3}$.

It is only within the past decade that researchers realized that Thorthormi could pose a threat. Thorthormi's ponds were expanding and merging to form larger bodies of water. The changes have been dramatic even in the past few months. "Just before we started our work here in July this year, that part of the lake was water," says Toeb, pointing down to a number of icebergs. "The ice blocks have been breaking off the mother glacier upstream.”

But the rate at which Thorthormi glacier is melting is not the only concern, says Toeb, motioning at the boulders underfoot. The moraine separating the Thorthormi and Rapstreng lakes is at places only around 30 metres wide and is prone to landslides. Geophysical testing in 2008 showed that the moraine contains a substantial amount of ice. As that ice melts, along with the rest of the glacier, the ridge could collapse, releasing the water from Thorthormi into Rapstreng below. Then there would be a combined outburst flood, Toeb says.

\section{Building pressure}

A four-year study led by Hermann Häusler from the University of Vienna in collaboration with Bhutan's geology and mines department predicted the moraine between Thorthormi and Rapstreng could give way as early as 2010 , because of the hydrostatic pressure of the growing Thorthormi glacial lake. A combined flood would unleash around 53 million cubic metres of water down the Pho river'.

Every country within the Himalayan region has suffered a glacial outburst flood at some point ${ }^{3}$, and Bhutan is no exception. A number of glaciers in that country are missing sections of their moraines, suggesting that lakes have burst there in the past. Half a century ago, floods originated from the Lunana region in northern Bhutan, which is home to Thorthormi and many other glaciers. The floods may have come from glacial lakes, but there were no studies of them at the time. The only scientifically documented glacial flood in Bhutan's history came from a lake at the bottom of Luggye glacier, on Thorthormi's eastern margin, 15 years ago.

Ponds first appeared on the Luggye glacier in the late 1960s, and by the early 1990s the glacier was retreating by up to 160 metres a year ${ }^{2}$. On 7 October 1994, the glacier's moraine broke and released an estimated 18 million cubic metres of water and debris down the Pho river, killing 21 people and razing fields and settlements downstream with a jumble of uprooted trees, boulders and mud.

Memories of that flood still haunt Dawa Gyeltshen, a herder who lives in the village of Taksho, beside the Pho river around 20 kilometres downstream of Luggye. He remembers being woken by a thunderous noise early that morning. For hours he raced around outside his house in the dark, terrified as the river rose.

It wasn't until dawn that Gyeltshen saw the extent of the damage. The forested river valley and a large portion of the fields in front of his house had been washed away and in their place were mounds of boulders and glacial silt. Today, the landscape is recovering. Pockets of shrubs and wildflowers have settled in along the river and Gyeltshen's remaining land is golden with this year's crop of buckwheat. White prayer flags line the rugged edge of the property, marking the course of the water during the flood. But even now, Gyeltshen says he still has trouble sleeping through the night, worried about another flood.

A combined flood from Thorthormi and Rapstreng lakes could cause at least ten times the damage and fatalities of the 1994 event $^{4}$. In the past 15 years, hospitals and schools have popped up along the river, along with a partially completed \$760-million, 1,200-megawatt hydropower dam project.

It was in part because of the 1994 disaster that Bhutan became a leader in adapting to climate change. Following the flood, scientists from Bhutan, Japan and Austria, among other 


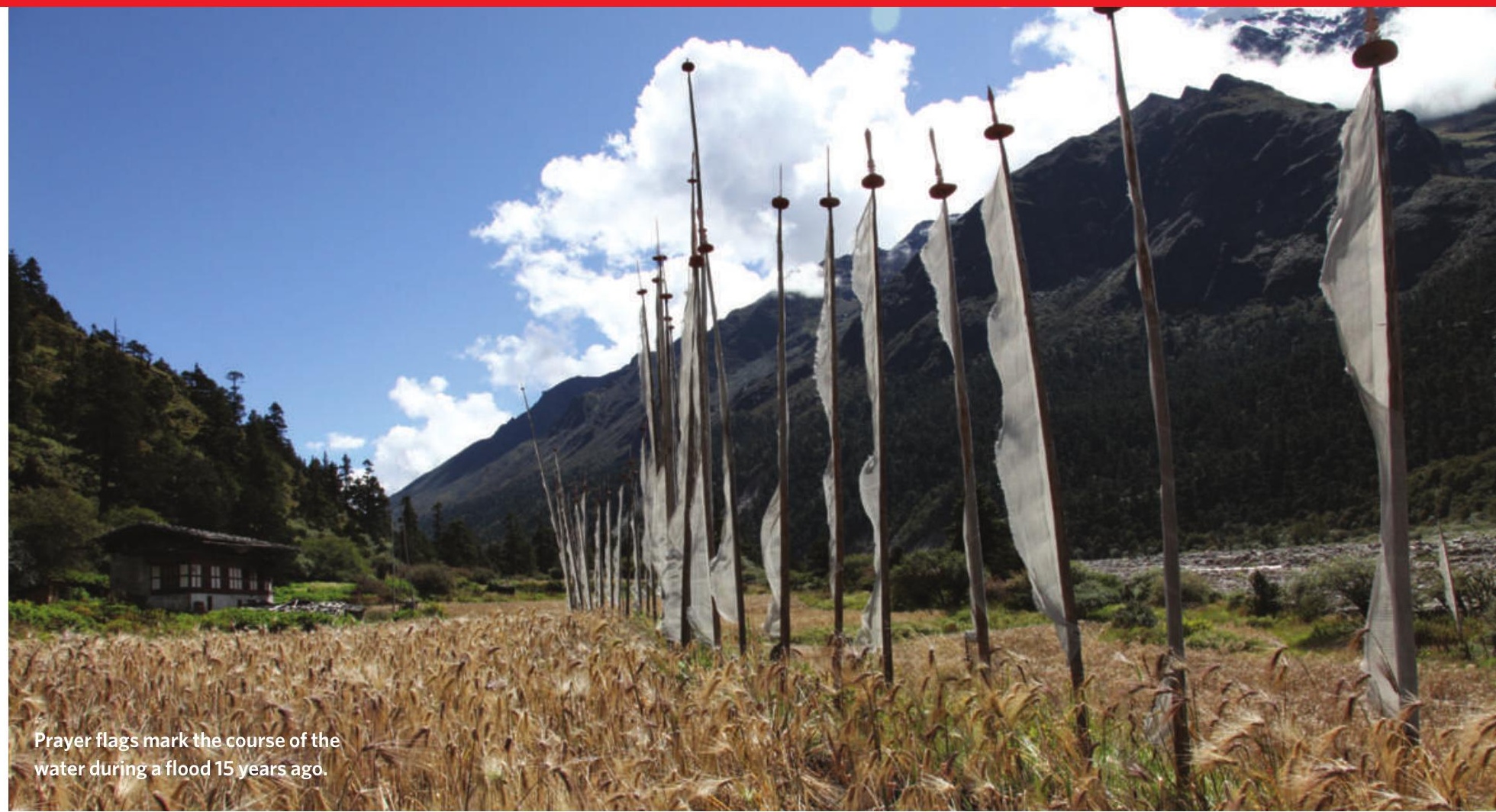

countries, launched research programmes into the glaciers in the Lunana region. When the Least Developed Countries Fund was created in 2001, "we had a lot of good information on glacial floods", says Thinley Namgyel, the deputy chief environment officer at the National Environment Commission in Thimphu.

\section{Gross national happiness}

Bhutan's work on adaptation is backed by a strong record of environmental protection. As a follower of the Buddhist tenet of non-extremism - the Middle Path - Bhutan's monarchy has stressed that modernization and economic development are important, but not at the expense of the country's natural environment and cultural traditions. In 1972, Bhutan's fourth King, Jigme Singye Wangchuck turned away from the classic yardsticks of growth, such as gross domestic product, to focus on a more holistic approach to his people's well-being. The measurement, which he called gross national happiness, is based on several measures of environmental and social contentment.

The country has some of the most progressive - and controversial - environmental regulations in the world, including bans on plastic bags, timber exports, hunting and even tobacco sales. They've also minimized tourist traffic by charging visitors to the country around $\$ 200$ a day.

The nation's proven environmental record, coupled with the immediacy of the risks of a glacial flood, made Bhutan's adaptation needs especially attractive to donors. "From the start,
Bhutan was in the driving seat," says Bonizella Biagini, a senior programme manager at the Global Environmental Facility, which manages the Least Developed Countries Fund. Other developing nations have been less successful in getting adaptation money through that fund. "If everyone behaved like Bhutan, every project would be in the process of being implemented," says Biagini.

Bhutan has also received $\$ 1.3$ million in adaptation support from other sources, including the Austrian Development Cooperation,

of the lake, the extreme altitude, the boulderstrewn terrain and the unpredictable weather $\frac{2}{z}$ have made the project logistically difficult.

The project's engineer, Karma Tenzin, had hoped originally to fly a couple of excavators to the site and do the digging in a few weeks. But soon after visiting Lunana this year, he realized an industrial solution would be difficult. The nearest potential helicopter landing was an hour and a half away by foot. Even if an excavator was brought in, it could topple on $\mathbb{x}$ the uneven terrain, says Tenzin. "Everywhere you look are boulders," he says. "Bringing in an excavator is useless."

The price was also a factor: without its own helicopter, Bhutan would have had to hire one from Nepal for several thousand dollars per trip. Because unemployment is rising in Bhutan, the project board reasoned that it would be better to pump the money into the country's economy - by paying local horsemen to transport the project's goods and by providing excavation jobs. So in July, in the middle of the monsoon season, hundreds of workers set off on the 9-day journey to Lunana from the capital. At the site, using shovels and spades, they load cobbles into strips of burlap and

the conservation group WWF Bhutan and the United Nations Development Programme.

Yet even with money and political willpower, the task is daunting. The main goal at Thorthormi glacier is to lower the lake's water level by 5 metres, which would reduce the hydrostatic pressure pushing on Thorthormi's unstable natural dam.

Under normal conditions, the lowering would be an easy task, but the remote location carry them to the sides of the channels. Boulders are broken crudely with blunt hammers and hauled off-site with weathered rope. At the end of September, a few jackhammers and chisels arrive to help split boulders. A shipment of rope also arrives, although Tenzin admits that it is unlikely to last long. "At least for the next two weeks we will be able to pull rocks," he says. "After that, the rope is likely to be all broken again." 
The working season for the project is less than four months a year, because snow blocks the path to the site for all but July to October. But heavy rainfall this year washed away several key bridges, delaying work for an additional month. "We almost cancelled the project for this year," says Dowchu Dukpa, the project's manager. "We thought: by the time we get there, we will have to go back."

But the project went ahead. When the last workers put down their tools for the year on 15 October, they had lowered the lake by around 90 centimetres. This was considerably less progress than the original goal of 1.67 metres for this first year, but the group thinks it can make up the difference during the next two years of the project. "I am sure the goal will be achieved," says Tenzin.

\section{Practical challenges}

Even if the final goal of 5 metres is achieved by 2011, glacial experts cannot say how much that will reduce the risk of a moraine burst. Part of the problem is the lack of basic information about the Thorthormi glacier and its lake.

The glacier is covered in boulders and silt, which makes it difficult to measure how quickly the ice is retreating, says Koji Fujita, a glaciologist from the University of Nagoya in Japan.

The lake's drifting icebergs also make a comprehensive bathymetric survey extremely dangerous, says Fujita. Bhutanese officials only took a few depth measurements in 2008 with a simple string and weight, because strong winds made it difficult to handle the boat. "We don't know how much water will come out of the lake or how fast it will flow in an outburst," says Fujita.

What's more, developing countries such as Bhutan don't have the technical and financial resources to study the changes that are happening in their countries. High-resolution satellite imagery can be expensive and the country can afford it only infrequently. Difficult and remote terrain also hampers their monitoring work. Every scientist and bit of instrumentation has to make the journey to Lunana on foot. To top it off, they are contending with a landscape that is rapidly changing because of global warming.

Project leaders reason that their strategy at Thorthormi must reduce the hazard there to some degree. "If the lake is lowered by some metres, that much pressure is released from the moraine wall," says Toeb. "So the chance of the moraine wall failure is less."

But Toeb admits that the work will not eliminate the possibility of a flood. "A piece of ice could detach from the mother glacier, fall into the lake and generate a surge wave," says Toeb. "Or if there is a big seismic event in this

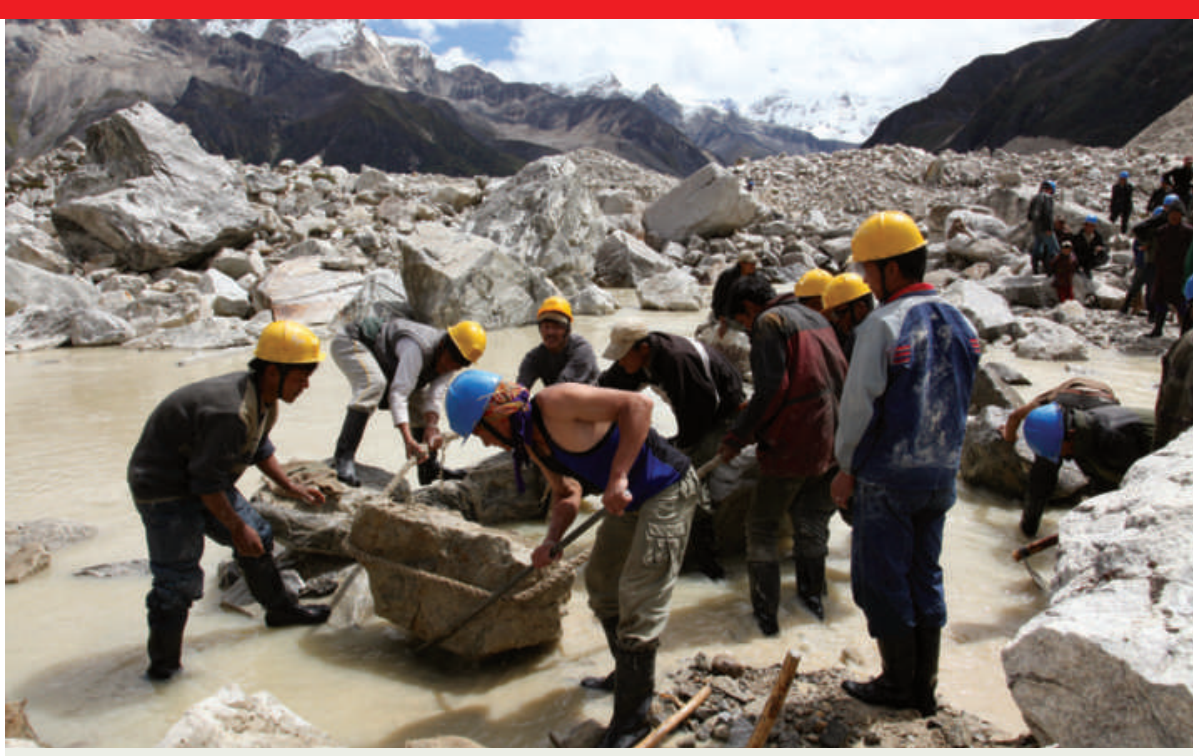

\section{The long wait for adaptation money}

The cruelty of climate change is that developing nations are the most vulnerable and least able to afford protective measures. To help them cover the billions of dollars it will cost to adapt, the United Nations Framework Convention on Climate Change set up funding mechanisms during climate talks in 2001.

The main source of money, the Least Developed Countries Fund (LDCF), is supported by donations from rich countries and currently has US\$176 million in pledges. The fund is managed by the Global Environmental Facility (GEF). To qualify for money, countries first need to itemize and prioritize their urgent needs in a document called the National Adaptation Programmes of Action (NAPA).

Although 42 countries have submitted their NAPA documents to date, only one country, Bhutan, has physically started implementing its projects. Developing countries blame this delay on the GEF's

"bureaucratic red tape".

The situation is improving; the GEF has endorsed projects in eight more countries so far this year. But there is another bottleneck: There isn't enough money in the LDCF to go around. Each developing country is limited to $\$ 5$ million, enough for only a fraction of their NAPA priorities. To implement all NAPA projects currently submitted, the fund would need around $\$ 1.7$ billion
- nearly ten times what it has been pledged by developed nations so far.

Bhutan is moving ahead with three of its nine NAPA priorities: capacity building for disaster management, lowering a glacial lake (shown above) and an early warning system for glacial floods. But the country is anxious to start on more of its priorities, says Thinley Namgyel, deputy chief environment officer at the National Environment Commission in Thimphu, who helped coordinate the country's adaptation plan. "We were told we had to wait until the LDCF is replenished," he says.

The Himalayan nation was the first to receive funding in part because it moved much faster than others. Bhutan was the first country to submit its fully completed NAPA, in 2006. It also lacks the degree of poverty and corruption that troubles many developing nations.

Most other developing nations have struggled with the process. Because the nations have less capacity to plan and implement adaptation projects, the GEF requires them to work through an implementing agency, such as the UN Development Programme (UNDP), the UN Environment Programme or the World Bank.

This architecture adds bureaucratic layers that slow the process. Although Bhutan's neighbour, Nepal, initiated its NAPA in 2002, the country still has not completed its initial prioritized list. Batu Uprety, joint secretary for the ministry of forests and soil conservation in Kathmandu, says Nepal's implementing agency, the UNDP, was more of a barrier than a facilitator.

Bonizella Biagini, who oversees the LDCF, says that reviews of NAPAs take at most 15 days. "When a project is submitted to us, we have to look to see if it meets the LDCF criteria," she says. "If it doesn't, I send it back. Sometimes it comes back in two weeks, sometimes it comes back in a year, sometimes the government folds."

Last December, during the last round of UN climate negotiations in Poznań, Poland, several developing countries complained that there was too much red tape involved in accessing GEF funds. They called for direct access to GEF funding. "If a country wants to work through an implementation agency that is fine," says Uprety. "But if a country doesn't want to, that shouldn't be a barrier."

It isn't clear whether the LDCF will survive in the next climate agreement, as developing countries look for easier ways to access money. A possible funnel for adaptation money in the next climate agreement is the Adaptation Fund, which was also set up in 2001 but has yet to accumulate much money or to distribute any funds. A.N. 


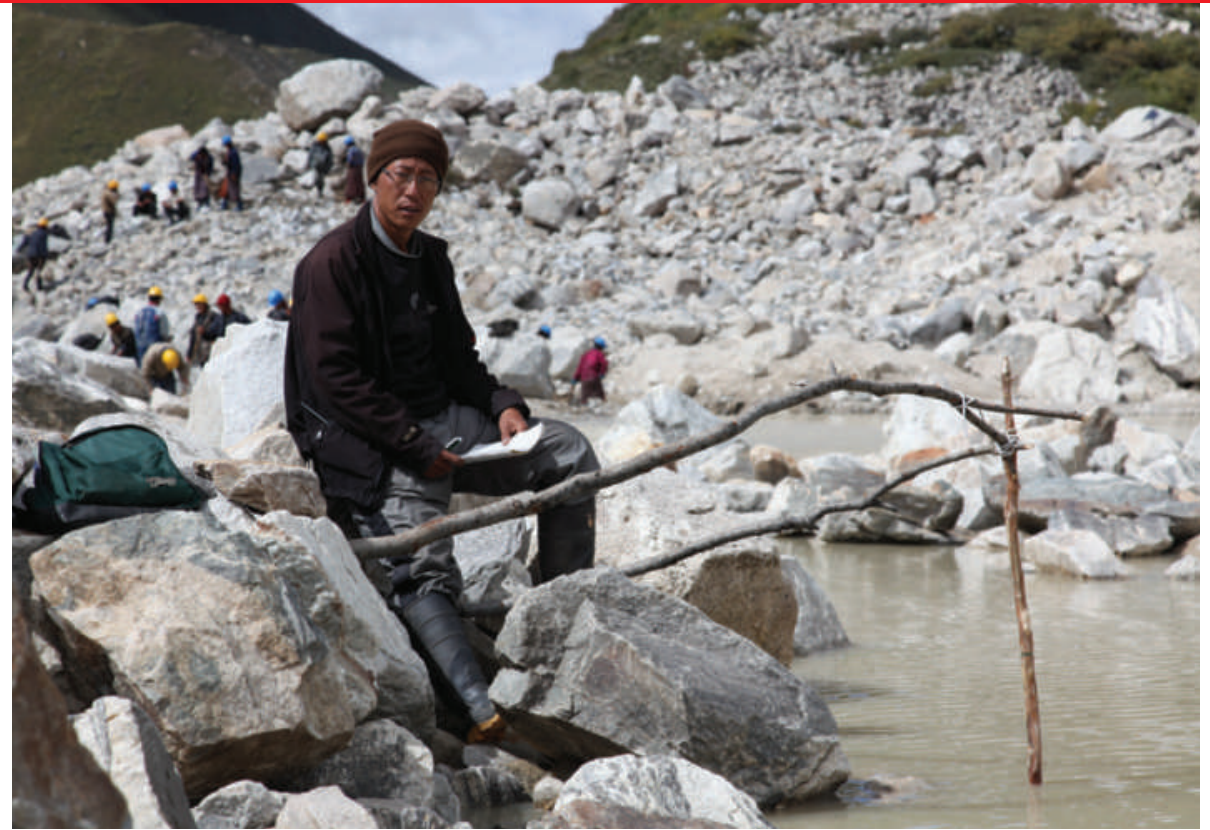

Karma Tenzin uses a stick to measure the level of Thorthomi lake.

area, the whole moraine wall surrounding the glacial lake may collapse."

Because artificially lowering Thorthormi isn't enough to prevent a flood, the government intends to install an automatic flood early warning system in the Pho river valley, which will also be paid for with money from the development fund.

The Bhutanese Department of Energy currently runs a manual warning system in the Lunana region. A couple of attendants equipped with a VHF radio and satellite phone are supposed to monitor the lakes and river three times a week. But the system isn't working. "We never see them at the site," says Toeb, who has reported the problem to the department.

The new automatic system will record the water levels using sensors. In the case of an outburst, the system would send out a signal to towers downstream to warn communities of an impending flood, potentially providing hours of advance notice.

Because Bhutan does not have the capacity or expertise to do the work on its own, its Department of Energy has put the project out to tender, in hopes of an international bid within its budget. Construction is expected to start next year, says Karma Chhophel, the head of the department's hydrological- and meteorological-services division.

The entire Thorthormi mitigation project will last at least four years and cost \$7.4 million. But Thorthormi is only one of thousands of glacial lakes in Bhutan. ICIMOD has identified 25 potentially dangerous lakes in Bhutan, but the list was based on crude satellite data ${ }^{2}$.

The centre will release an updated inventory of dangerous lakes in Bhutan next year based on satellite imagery with "better spectral, spatial and temporal resolution", says Pradeep Mool, a remote sensing specialist with ICIMOD, who was involved in the study. The inventory will also rank lakes based on socioeconomic information, including the potential loss of life and damage to infrastructure. "All the lakes need attention," he says. "But we have to prioritize where we do the big-scale mitigation work, the early-warning system, and the hazard zonation maps."

\section{Spy data}

But qualitative analysis of satellite images isn't enough to determine which lakes are dangerous, according to Fujita. He is trying to develop quantifiable criteria, such as the angle between the level of the water in the glacial lake and the slope of the moraine, that dictate a moraine's stability and the likelihood of a glacial outburst. His team is testing that hypothesis by comparing new satellite images with data from old American spy satellites to create digital elevation models of lakes that burst in the past. The researchers will also develop their own list of the region's dangerous lakes next year, but the results are likely to be substantially different from ICIMODs, says Fujita. "Some of its 25 dangerous lakes are not a hazard, but we found more that ICIMOD did not point out," he says.

Regardless of which lakes are a risk now, the number will rise in the future, as glaciers continue to melt. "Thorthormi is a very good lesson," says Toeb. "Nobody knows what will happen, taking into account all the changes in climate; the same situation may happen to any of the glaciers in Bhutan."

Although glacial lake bursts cause considerable damage in the Himalayas, an even bigger catastrophe would come from the disappearance of those very same glaciers, and the water they produce, which is predicted within the next few decades. That loss could significantly harm the $69 \%$ of the Bhutanese population that relies on farming, mostly subsistence. A decrease in water flow could also seriously affect the country's plan to boost its hydropower production by 10 gigawatts by 2020 . "We don't know the medium- or long-term costs of climate change in Bhutan," says Namgyel. "A few decades down the line, the glaciers will retreat and we are not sure what impact it will have on the economy."

The impacts will reach far beyond Bhutan's borders. The glacier-fed rivers that flow south from the Himalayas are the arteries of south Asia. It is estimated that the retreat of glaciers will affect the water supply of roughly $750 \mathrm{mil}-$ lion people across South Asia and China, says Rajendra Pachauri, the chairman of the Intergovernmental Panel on Climate Change.

Across Asia, there are countless cases like Thorthormi, where the needs are great and the resources scarce. Regarding the effects of climate change and their costs, "every single estimate that people have come up with has been exceeded by reality", says Pachauri. "The impacts of climate change are clearly turning out to be much worse than what we had anticipated earlier."

Standing on Thorthormi's natural dam, the scale of the problems ahead strain the imagination. From here, the sounds of the labourers struggling 100 metres below fade to whispers on the wind. At this distance, it is impossible to see their frost-bitten cheeks, or the cuts and bruises earned during their months of labour. In a line of 30 people, they look like a caterpillar pulling pebbles across a path. They are dwarfed by the size of the lake, the glaciers above, and the rest of the world, as it tries to keep pace with the changing climate.

Anjali Nayar is an International Development Research Centre fellow at Nature.

\footnotetext{
1. Cruz, R. V. et al. Asia. Climate Change 2007: Impacts, Adaptation and Vulnerability. Contribution of Working Group II to the Fourth Assessment Report of the Intergovernmental Panel on Climate Change (eds Parry, M. L., Canziani, O. F., Palutikof, J. P., van der Linden, P. J. \& Hanson, C. E.) 469-506 (Cambridge Univ. Press, 2007).

2. Bajracharya, S. R., Mool, P. K. \& Shrestha, B. Impact of Climate Change on Himalayan Glacier and Glacial Lakes: Case Studies on GLOF and Associated Hazards in Nepal and Bhutan (ICIMOD, 2007).

3. Mool, P. K. et al. Inventory of Glaciers, Glacial Lakes, and Glacial Lake Outburst Floods: Monitoring and Early Warning Systems in the Hindu Kush-Himalayan Region, Bhutan (ICIMOD, 2001).

4. Brauner, M., Leber, D. \& Hausler, H. Glacier Lake Outburst Flood (GLOF) Mitigation Project, Lunana, Bhutan, Technical Mitigation Measures Thorthormi Outlet. (Department of Geological Sciences, University of Vienna, 2003).
}

See Editorial, page 1027, and online at www.nature.com/roadtocopenhagen. Watch a video at go.nature.com/VGGayN. 